\title{
Integração analítica da micro e da macroeconomia: algumas reflexões teórico-metodológicas *
}

\author{
Fernanda Graziella Cardoso **
}

\begin{abstract}
Resumo
Partindo de um esforço de síntese de contribuições teóricas alternativas ao mainstream da Economia Simon, Keynes e pós-keynesianos, Kalecki, Schumpeter e neoschumpeterianos e abordagem da complexidade -, o presente artigo discute algumas das limitações ao progresso da Ciência Econômica, enquanto ciência e base para formulação de políticas, impostas por um enfoque baseado nas premissas da maximização e do equilíbrio. Sugerem-se, desse modo, algumas das possibilidades de avanço deixadas em aberto por meio da superação dessas premissas, apontando especialmente para aquela que seria uma abordagem interessante ao objeto da Economia, a micromacrodinâmica, levando em consideração seu caráter dinâmico e complexo.
\end{abstract}

Palavras-chave: Ciência econômica; Maximização; Equilíbrio; Complexidade; Micromacrodinâmica.

\begin{abstract}
Analytical integration of the micro and macroeconomy: theoretical-methodological reflections

Based on a synthesis of alternative theoretical contributions to mainstream economics - Simon, Keynes (and post-keynesians), Kalecki, Schumpeter (and neo-schumpeterians) and the theory of complexity -, this paper discusses some of the limits to the progress of economics, as a science and a foundation for constructing policies, imposed by an approach based on the premises of maximization and equilibrium. It is suggested that some of the possibilities of advancement are left open by the overcoming of these premises, pointing especially to one that would be an appropriate theory to the object of the economic science, the micro-macrodynamic approach, considering its dynamic and complex nature.
\end{abstract}

Keywords: Economics; Maximization; Equilibrium; Complexity; Micro-macrodynamic.

JEL B29, B50.

\section{Introdução}

Mesmo partindo de bases distintas, qualquer enfoque teórico da Ciência Econômica se propõe a explicar o mesmo objeto, o funcionamento do sistema econômico. No entanto, seja qual for o enfoque ou delimitação teórica, para se definir uma boa teoria é fundamental a discussão das premissas nas quais se baseia, uma vez que entre os deveres de uma teoria científica está o de explicar o seu objeto de investigação e não apenas (ou mesmo necessariamente) o de realizar previsões acuradas.

* Artigo recebido em 30 de março de 2009 e aprovado em 29 de setembro de 2016.

** Professora dos Bacharelados de Ciências Econômicas e de Relações Internacionais da Universidade Federal do ABC (UFABC), São Bernardo do Campo, SP, Brasil. E-mail: fernanda.cardoso@ufabc.edu.br. 
Com vistas a tal princípio, argumenta-se que o equilíbrio, sendo um pressuposto metodológico ${ }^{1}$, distorceria aquele que deveria ser o objetivo de uma teoria que tem como objeto algo intrinsecamente dinâmico, como a Economia. A maior parte dos resultados importantes e interessantes do funcionamento do sistema econômico ocorre fora de estados de equilíbrio.

O comportamento maximizador também não é um pressuposto sem problemas. Por trás dele encontra-se a racionalidade substantiva (Simon, 1979), a qual imputa aos agentes uma capacidade cognitiva, de processamento de informação, de aprendizado e de previsão impensável não só para os mais modernos computadores como para os mais racionais dentre os indivíduos. Nesse caso, não se trata apenas de superar a premissa de informação perfeita, mas de reconhecer a limitação cognitiva dos agentes - que nem por isso deixam de ser racionais - que os impede de se aproximar de um comportamento dessa natureza frente à enorme complexidade do ambiente em que agem.

Vale observar também que a crítica aqui exposta não se pauta unicamente na necessidade de uma maior aproximação da teoria à realidade, mesmo porque, por definição, uma teoria é apenas uma tentativa de representá-la. A crítica se dirige principalmente ao obstáculo ao progresso da análise econômica representado por um enfoque teórico que não se preocupe, em algum grau, com o irrealismo de seus pressupostos. É nesse contexto de abandono, em diferentes graus, do equilíbrio como pressuposto metodológico e da superação dos limites impostos pelo princípio da racionalidade substantiva (maximizadora) que as contribuições originais de Keynes (1936), Kalecki (1954), Schumpeter (1912, 1943) e Simon (1979), e os desenvolvimentos subsequentes dos pós-keynesianos e dos neoschumpeterianos ${ }^{2}$, bem como as discussões levantadas pela recente abordagem da complexidade, se apresentam como inovadoras e especialmente pertinentes ao tema proposto pelo presente trabalho - o de refletir sobre os possíveis benefícios ao progresso da análise econômica de um enfoque teórico que se volte para a interação dinâmica entre a micro e a macroeconomia e que busque considerar a dimensão de complexidade das questões econômicas.

Quanto à sua estrutura, o artigo divide-se em duas seções além desta introdução e das considerações finais. A primeira seção se divide em três subseções: em 1.1, discute-se a inadequação dos pressupostos do equilíbrio e da maximização;

(1) Na perspectiva teórica (neo)clássica, o equilíbrio, geralmente a partir de hipóteses fortes, é suposto como necessário - aliás, aparece muitas vezes como sinônimo de solução. A crítica aqui sugerida dirige-se ao fato de o equilíbrio, colocado como pressuposto metodológico, aparecer indevidamente (sem justificativa) como indispensável para a realização de análises econômicas.

(2) O trabalho de síntese e de revisão crítica das contribuições de Keynes, Kalecki e Schumpeter, bem como dos pós-keynesianos e dos neoschumpeterianos, com o objetivo de integrar analiticamente a micro e a macroeconomia foi originalmente realizado por Possas $(1983,1984)$. 
em 1.2, apresentam-se alguns conceitos da abordagem da complexidade; e, em 1.3, inicia-se a discussão do interesse de uma integração analítica da micro e da macroeconomia. A segunda seção também se divide em três subseções: em 2.1, sugerem-se alguns requisitos teórico-metodológicos para lidar com a complexidade da economia; em 2.2, discutem-se algumas contribuições teóricas de uma abordagem que integre analiticamente a micro e a macroeconomia; e em 2.3, aventam-se algumas aplicações micro macrodinâmicas de elementos teóricos alternativos ao mainstream.

\section{Algumas considerações teórico-metodológicas a partir de Simon e da abordagem da complexidade}

Nessa primeira seção, discutem-se criticamente alguns temas relacionados às opções teóricas e metodológicas que guiaram a consolidação da Ciência Econômica, especialmente no que diz respeito ao paradigma neoclássico.

\subsection{Os pilares teóricos neoclássicos: o equilíbrio e a maximização}

A teoria econômica neoclássica construiu suas bases sobre dois principais pilares: o da maximização e o do equilíbrio. Vercelli (1991) realiza uma importante distinção entre uma noção dita sintática e outra dita semântica de equilíbrio. Segundo o autor, a noção sintática se refere ao equilíbrio como um conjunto de valores que satisfaria uma série de condições que necessitam ser cumpridas simultaneamente. Tal noção excluiria, por definição, a possibilidade lógica de uma posição fora do equilíbrio e, em geral, baseando-se nela, define-se a solução de um sistema de equações como um equilíbrio ${ }^{3}$. No entanto, o autor observa que, de um ponto de vista estritamente sintático, a solução de um sistema de equações seria simplesmente o conjunto de valores que tornaria tal sistema logicamente aceitável. Já a noção semântica de equilíbrio traria consigo um significado que vem desde Adam Smith: equilíbrio ponto resultante de uma tendência. As situações fora do equilíbrio seriam, então, logicamente possíveis. De acordo com o conceito dinâmico de equilíbrio, um sistema estaria em equilíbrio sempre que não gerasse um processo dinâmico endógeno. Assim, uma condição necessária e suficiente para que se defina um sistema dinâmico como em desequilíbrio é que ele exiba um comportamento dinâmico endógeno.

Segundo Possas (1987), é imprescindível destacar a importância do tempo para que realmente se constitua uma análise de natureza dinâmica: "[a] aplicação analítica de uma teoria dinâmica a uma situação econômica concreta pressupõe a "conversão" de uma trajetória determinada no tempo teórico ${ }^{4}$ e/ou histórico para o

(3) Ou seja, como se equilíbrio fosse igual à solução, e vice-versa, configurando uma relação de identidade.

(4) Tal conceituação de tempo se refere à influência do passado e das expectativas futuras sobre o presente e do presente sobre o futuro (Possas, 1987, p. 25). 
tempo cronológico" (Possas, 1987, p. 25). O que, vale destacar, não se trata de uma tarefa simples. No entanto, "A persistência em um esforço de construção teórica de alguma amplitude, em particular quanto à dinâmica econômica, é uma aposta, e como tal envolve riscos e só pode ser avaliada por seus resultados: o eventual acréscimo de poder explicativo" (Idem, p. 33).

Quando há dependência de trajetória e indeterminação, as comparações entre diferentes sistemas deveriam ser realizadas com base em um método de dinâmica comparativa. De acordo com Vercelli, a importância de posições de desequilíbrio e do comportamento dinâmico em desequilíbrio deve ser atribuída aos próprios agentes econômicos. Conforme observa o autor, "[S]ince a disequilibrium position generates profitable opportunities for arbitrage, there is no reason to deny that rational economic agents are capable of discovering and exploiting such opportunities in their personal interest" (Vercelli, 1991, p. 33).

Knudsen argumenta que é impossível encontrar uma solução não ad hoc para o problema do ajustamento ao equilíbrio dentro do paradigma da racionalidade substantiva. Por conta da interação social, cada agente formará expectativas acerca das decisões a serem tomadas pelos outros agentes do sistema. Assim, para obter uma solução não ad hoc para o problema do ajustamento ao equilíbrio, seria necessário explicar o processo dinâmico por meio do qual o equilíbrio é alcançado, baseando-se no processo de tomada de decisão racional dos indivíduos - o que incluiria ainda o processo de formação de expectativas deles. $\mathrm{O}$ autor então se questiona: "[h]ow can several agents in an interactive environment simultaneously form beliefs about each other's decisions in a rational and conscious way?" (Knudsen, 1993, p. 147). E responde que, devido ao problema da autorreferência, parece ser impossível especificar esse procedimento.

Boland (1986) aponta que não faz sentido formular o equilíbrio somente no abstrato e não explicar concretamente como é atingido. Em geral, só são discutidas as propriedades do equilíbrio, tais como existência, estabilidade e unicidade. Portanto, a teoria neoclássica não possuiria uma teoria do equilíbrio, pois não explicaria nem o não-equilíbrio, tampouco como os agentes se ajustam ou balizam suas decisões para que o sistema tenda para o equilíbrio. $\mathrm{O}$ autor ainda advoga pela necessidade de microfundamentação ${ }^{5}$ e enfatiza que o problema da teoria neoclássica não é supor informação perfeita, e sim aprendizado perfeito.

(5) Essa questão representa um dos eixos centrais de discussão deste artigo. Como será argumentado adiante, a necessidade da microfundamentação decorre, em linhas gerais, da importância em se compreender o processo de tomada de decisão e de ação dos agentes. Ademais, a natureza desta microfundamentação é também fundamental. Sugere-se, por exemplo, que uma microfundamentação adequada à natureza complexa e adaptativa da economia deveria levar em conta a incerteza, e por isso também a impossibilidade do exercício de racionalidade substantiva por parte dos agentes. 
Por conseguinte, o equilíbrio seria um pressuposto metodológico - no sentido de ser encarado como indispensável - pois, além de nortear - e principalmente limitar - a análise econômica, tampouco se discute de maneira satisfatória a forma pela qual é atingido. Segundo Knudsen, tal opção metodológica explicaria a manutenção teórica do conceito de racionalidade substantiva, o qual "[h]istorically has been closely linked with the static type of analysis and not a procedural concept of rationality intended for more process-oriented types of analysis" (Knudsen, 1993, p. 145).

Knudsen enfatiza ainda que um programa de pesquisa baseado no conceito de racionalidade substantiva encontra uma série de problemas conceituais fundamentais para modelar a interação entre os agentes e em explicar como situações de equilíbrio emergem como resultado de deliberações racionais dos indivíduos. $\mathrm{O}$ autor aponta também para o fato de que a maioria dos problemas empíricos que os teóricos tentam resolver não parece originar-se da falsificação das previsões, mas sim do impedimento que o próprio programa de pesquisa dominante coloca para o reconhecimento de certos problemas. Em outras palavras, a limitação teóricometodológica funciona como uma lente inadequada, distorcendo ou desviando a atenção de questões muitas vezes importantes e/ou concentrando esforços em falsas questões.

Simon (1978) indica que, quando o sistema é complexo e o ambiente está em constante mudança, nada assegura que a posição momentânea do sistema residirá próxima a algum ponto de equilíbrio, seja ele global ou local. Em situações complexas, conclui o autor, uma teoria da racionalidade deve se preocupar tanto com as características dos agentes quanto com as características objetivas do ambiente em que tomam decisões. Por isso deve ser levada em consideração a racionalidade procedimental. $^{6}$

Simon (1959) argumentou que, quando a previsão perfeita não é possível por conta da incerteza, a definição de racionalidade deve ser estendida de maneira a levar em conta a predição e a formação de expectativas. Ademais, limitar a definição de racionalidade em decorrência da incerteza levanta ainda outra questão: a diferença entre o verdadeiro ambiente em que o agente vive e aquele ambiente percebido de maneira subjetiva. Dessa maneira, não é plausível tentar prever o comportamento dos agentes baseando-se apenas nas características objetivas do ambiente: faz-se necessária também a investigação dos processos perceptivos e cognitivos dos agentes. Conforme argumenta Simon (1979), a presença de incerteza impossibilita que um comportamento seja substantivamente racional.

(6) O comportamento racional procedimental é definido por Simon (1979) como "[t]he outcome of appropriate deliberation. Its procedural rationality depends upon the process that generated it" (1979, p. 68). 
Para a teoria econômica lidar com a incerteza, deve compreender como os agentes se comportam frente à sua presença e quais são os limites de informação e de processamento dela que tais agentes apresentam. A racionalidade procedimental far-se-ia presente em situações nas quais são necessários a coleta e o processamento de várias formas de informação a fim de solucionar racionalmente um determinado problema. Assim, a teoria da racionalidade não seria uma teoria de soluções ótimas - como implicaria uma teoria baseada na racionalidade substantiva - mas sim uma teoria de procedimentos eficientes para encontrar boas soluções ${ }^{7}$. Segue-se que, um enfoque baseado na racionalidade procedimental permite uma diversidade de comportamentos, vis-à-vis o agente representativo maximizador. A diversidade potencial de comportamentos implica, por sua vez, imprevisibilidade e mais incerteza.

Discorrendo sobre o comportamento estratégico, Elster (1979) ressalta que os agentes não apenas realizam suas escolhas baseados em suas expectativas sobre o futuro, como também baseados nas expectativas sobre as expectativas dos outros. Mas, em um ambiente caracterizado por incerteza forte, não se trata de qualquer comportamento estratégico. Diferentemente de um comportamento do tipo maximizador, pode-se dizer que os agentes, sob incerteza, se comportam de maneira criativa. De acordo com Dosi e Egidi (1991), em geral, a incerteza relacionada ao comportamento humano se deve à insuficiência de conhecimento para lidar com eventos relacionados ao futuro. À semelhança da distinção sobre racionalidade realizada por Simon (1979), os autores definem a noção de incerteza substantiva e de incerteza procedimental. A incerteza substantiva estaria relacionada a alguma falta de informação enquanto que a procedimental estaria relacionada a alguma falha de capacidade de processamento.

Talvez o mais interessante a ser ressaltado seja o fato de que tal incerteza é consequência, em última instância, dos próprios agentes do sistema. E, baseando-se em tal constatação, vale destacar a importância da microfundamentação da análise. Sendo os agentes econômicos - conforme será enfatizado na próxima seção -, capazes de pensar/agir de maneira estratégica, num ambiente caracterizado por incerteza forte, o resultado é uma ampla gama de comportamentos possíveis, igualmente racionais.

Sobre esse ponto, vale ainda destacar um comportamento com grande potencial de provocar instabilidade: o inovador. O mecanismo contínuo de mudança estrutural seria, portanto, uma explicação para a chamada instabilidade estrutural, a qual intrinsecamente caracterizaria os sistemas complexos, como o sistema econômico capitalista. Nas palavras do pós-keynesiano Davidson (1982):

(7) Ou, em outras palavras, ao invés do comportamento maximizador implicado por uma caracterização de racionalidade substantiva, a partir da racionalidade procedimental, seria definido um comportamento satisficing. 
If entrepreneurs have any important function in the real world, it is to make crucial $^{8}$ decisions. Entrepreneurship, which is but one facet of human capacity, must involve cruciality. To restrict entrepreneurship to robot decision-making via Bayes' theorem, as the REH ${ }^{9}$ does, is to provide a descriptive analogy of modern real world economies which ignores the role of the Schumpeterian entrepreneur - the creator of technological revolutions and change. The REH model is a beguiling representation of entrepreneurial decision-making in a world where crucial decisions are never made (Davidson, 1982, p. 193.)

Essa instabilidade decorrente de mudanças estruturais endógenas, características do sistema capitalista, implicaria necessariamente alto grau de imprevisibilidade. Então, conclui Vercelli, "[t]he economic agent has to face a disturbing amount of 'structural uncertainty' over the future evolution of the structure of the environment ('environmental uncertainty') and of the economic system ('systemic uncertainty')" (Vercelli, 1991, p. 71.).

Seria então viável e interessante, do ponto de vista da ciência enquanto detentora de funções sociais - quais sejam, contribuir para a geração de bem estar social -, basear a Ciência Econômica nos pressupostos de "equilíbrio e maximização"? Por enquanto, ao que tudo indica, parece que não. Vejamos nas seções seguintes elementos teórico-metodológicos que fornecem substratos para um tratamento alternativo da Economia.

\subsection{Reflexões a partir da abordagem da complexidade}

Segundo Foley (2003), a teoria da complexidade representa um esforço ambicioso de analisar o funcionamento de sistemas altamente organizados, mas descentralizados, compostos por diversos elementos heterogêneos. O método da teoria da complexidade é altamente empírico e indutivo e os modelos construídos sob a ótica dessa abordagem, em geral, envolvem o estudo da interação de um grande número de componentes em simulações computacionais com o objetivo de identificar propriedades emergentes generalizáveis. Além disso, uma característica comum a esses sistemas complexos é que seus componentes e regras de interação são não lineares. Os computadores desempenhariam então um papel crucial nesse tipo de pesquisa, pois se torna extremamente trabalhoso - senão impossível - inferir diretamente a dinâmica de sistemas não lineares caracterizados por alto grau de complicação.

(8) Ao utilizar o termo "crucial", Davidson (1982) se refere à definição desenvolvida por Shackle (1955). Uma decisão crucial no sentido adotado por esse autor significa que "[W]hen agents make crucial decisions, they necessarily destroy any ergodic stochastic processes that may have existed at the point of time of the decision" (1982, p. 192).

(9) Hipótese de expectativas racionais. 
Os sistemas complexos, conforme argumenta Arthur (2005), surgem naturalmente na economia. Os elementos do sistema - os agentes econômicos reagem estrategicamente e de maneira criativa ao considerarem os resultados que podem se seguir como consequência da ação que venham a realizar. E é exatamente a particularidade desses agentes que adiciona à economia uma complicação que não existe nas ciências naturais ${ }^{10}$. Nas palavras de Gleiser:

Sempre existiram dois problemas em tentar se construir uma teoria econômica de forma reducionista. O primeiro é que a economia é composta por seres humanos (...) com seus caprichos, emoções e fobias. O segundo é a questão da tecnologia. As tecnologias mantêm a economia em constantes mudanças (Gleiser, 2002, p. 119).

De acordo com Kirman (1999), as diferenças entre a abordagem dos economistas tradicionais e a dos adeptos da teoria da complexidade residem tanto na concepção sobre estabilidade quanto sobre a velocidade do ajustamento para o equilíbrio. A concepção econômica tradicional advoga que os indivíduos aprendem relativamente rápido - e por isso se comportam de maneira otimizadora - e que o ambiente econômico se modifica de maneira suficientemente lenta; por conseguinte, tem-se uma situação na qual os indivíduos não têm necessidade de continuar a aprender. Aqueles que compartilham da ideia de que a economia é um sistema complexo adaptativo argumentam que os processos de aprendizagem e adaptação e o próprio feedback das consequências daquela adaptação - geram uma dinâmica altamente complicada, impossibilitando a convergência para um equilíbrio econômico padrão. Segundo Holland (1995):

[w] will view cas $^{11}$ as systems composed of interacting agents described in terms of rules. These agents adapt by changing their rules as experience accumulates. In cas, a major part of the environment of any given adaptive agent consists of other adaptive agents, so that a portion of any agent's efforts at adaptation is spent adapting to other adaptive agents. This one feature is a major source of the complex temporal patterns that cas generate. To understand cas we must understand these ever-changing patterns (Holland, 1995, p. 10).

Perona (2004) argumenta que os modelos construídos sob a ótica da abordagem da complexidade pretendem ser mais flexíveis e abrangentes do que os

(10) Para ilustrar a complicação adicional da economia entendida como um sistema complexo, vale reproduzir uma interessante nota de rodapé em que Keynes cita que Max Planck, o famoso criador da Teoria Quântica, desistiu de estudar Economia porque essa lhe parecia muito difícil: "Professor Planck could easily master the whole corpus of mathematical economics in a few days. He did not mean that! But the amalgam of logic and intuition and he wide knowledge of facts, most of which are not precise, which is required for economic interpretation in its highest form is, quite truly, overwhelmingly difficult for those whose gift mainly consists in the power to imagine and pursue to their furthest points the implications and prior conditions of comparatively simple facts which are known with a high degree of precision" (CW X, 186n).

(11) Sistemas adaptativos complexos. 
modelos tradicionais, uma vez que levam em consideração uma dinâmica muito mais rica, a heterogeneidade dos agentes e a importância das instituições. Destacando as diferenças entre os modelos baseados na teoria econômica tradicional e os baseados na abordagem da complexidade, a autora ressalta que em ambos a unidade de análise é o indivíduo, porém, sob a perspectiva da complexidade, o suposto da prática de racionalidade não é sinônimo de otimização. Os agentes econômicos não seriam então vistos como átomos passivos, e sim como autômatas que se adaptam de forma ativa. As interações, prossegue a autora, podem ser globais ou locais e a ideia de agente representativo ${ }^{12}$ é descartada em favor da consideração explícita da heterogeneidade e das relações entre os agentes.

Novamente de acordo com Arthur (2005), a economia neoclássica tradicional apresentaria como questão norteadora quais ações, estratégias ou expectativas dos agentes estariam em conformidade com o padrão que esses comportamentos criam de maneira agregada. A abordagem da complexidade permitiria, por sua vez, questionar algo mais abrangente: quais ações, estratégias ou expectativas dos agentes podem reagir aos padrões que elas criam? Ou seja, tal abordagem alternativa tornaria possível a análise de como a economia se comporta fora do equilíbrio, não constituindo, portanto, um mero complemento à teoria neoclássica, e sim uma forma mais geral e abrangente de encarar os fenômenos econômicos.

Prado contrapõe dois modos de tratar as unidades econômicas, as suas interações e os resultados conjuntos de tais ações individuais: o reducionista e o sistêmico. No primeiro caso, os todos econômicos seriam entendidos como agregações; no segundo caso eles seriam compreendidos como sistemas ou como composições globais, já que, "[a]s interações que os constituem, constituem em processo também os próprios agentes enquanto tais" (Prado, 2006, p. 305).

Ademais, complementa Prado, a análise da interação entre os indivíduos, sob a perspectiva de um método sistêmico, deve ser necessariamente dinâmica:

[A] interação dos indivíduos condicionada pela estrutura define o modo de composição do sistema, que, por sua vez, modifica em processo o comportamento dos indivíduos. Por isso, a explanação aqui é necessariamente dinâmica. O movimento sintético que explica a propriedade macroeconômica parte dos indivíduos, mas o faz também pela composição do sistema (Prado, 2006, p. 310).

(12) Sobre tal definição, vale destacar que "[o] todo, enquanto propriedade emergente, não é dedutível imediata e diretamente a partir de certo "componente representativo". Em verdade, uma vez que a abordagem da complexidade representa um esforço intelectual ambicioso de compreensão do funcionamento de sistemas altamente organizados, porém descentralizados e compostos de um número muito grande de componentes individuais, heterogêneos, a própria noção de "componente representativo" é insuficientemente representativa" (Cardoso; Lima, 2008, p. 360) 
Assim, em linhas gerais, de acordo com Arthur, Durlauf e Lane (1997), podem ser identificadas algumas características fundamentais dos sistemas econômicos complexos: são sistemas compostos por agentes idiossincráticos com potencial de aprendizado e adaptação; ocorrem interações entre os agentes do sistema que são coordenadas por normas, instituições e organizações endógenas, e não há nenhum mecanismo global de controle; tais sistemas podem apresentar mecanismos de auto-organização e estruturas emergentes que resultam tanto da agregação quanto da interação de suas partes. E, por conta dessas características, o novo emerge recorrentemente no sistema econômico. Logo, o sistema econômico encontra-se em permanente processo de adaptação e renovação e opera, em geral, fora do equilíbrio, conforme o sentido clássico do termo.

A abordagem da complexidade permitiria então a consideração de uma série de características do sistema econômico que não são exploradas e explicadas de modo satisfatório pela teoria econômica de orientação neoclássica, baseada nos pressupostos de equilíbrio e maximização. Tal perspectiva teórico-metodológica alternativa auxiliaria, em larga medida, na busca por elementos que fundamentem uma análise dinâmica e interativa entre os níveis micro e macroeconômico. Este tema será introduzido na próxima seção e manter-se-á presente em todo o desenvolvimento subsequente.

\subsection{Em direção à integração dinâmica da micro e da macroeconomia}

Conforme argumentado na subseção 1.2, a complexidade do sistema econômico se origina em boa parte da própria complexidade dos agentes do sistema, os quais são dotados de capacidade estratégica, criatividade e caracterizados por uma grande heterogeneidade. Os agentes econômicos, dada a incerteza do ambiente interativo, reagem de forma estratégica e criativa, o que deixa em aberto uma miríade de possibilidades de ação igualmente racionais. Assim, por meio do abandono do pressuposto de comportamento racional maximizador e da contestação do pressuposto metodológico do equilíbrio, abre-se um grande espaço para a análise dos comportamentos possíveis dos agentes a partir de suas limitações frente à complexidade do processo de tomada de decisão que precisam realizar e, por conseguinte, também para a análise das diversas trajetórias que podem resultar desse processo e das várias interações que se seguem.

Como já dito, o presente trabalho apresenta como ponto de partida a ideia de que a economia é um sistema dinâmico complexo. Nas palavras de Gleiser, "[é] necessário encarar o fenômeno econômico como um sistema evolutivo e dinâmico, em vez de um sistema em busca do crescimento equilibrado estável. Para sistemas dinâmicos complexos, equilíbrio é igual à morte" (Gleiser, 2002, p. 13). 
Pretende-se sugerir também que na investigação do comportamento dos agentes reside uma das chaves para a compreensão adequada do funcionamento do sistema econômico. Lembrando as palavras do velho institucionalista Thorstein Veblen:

[T]he physical properties of the materials accessible to man are constants: it is the human agent that changes, - his insight and his appreciation of what these things can be used for is what develops (...) It is in the human material that the continuity of development is to be looked for; and it is here, therefore, that the motor forces of the process of economic development must be studied if they are to be studied in action at all. Economic action must be the subjectmatter of the science if the science is to fall into line as an evolutionary science (Veblen, 1898, p. 388).

A partir da intuição da centralidade da decisão individual em um ambiente complexo e incerto para a compreensão da dinâmica do sistema econômico, demarca-se o primeiro passo a ser dado em direção a uma teoria que integre dinamicamente a micro e a macroeconomia: uma microfundamentação adequada a sistemas complexos. Mas como inferir o que resulta no nível macroeconômico? Para tal, faz-se patente, além de uma microfundamentação adequada, a análise de como se desenvolve a dinâmica de interação dos agentes, de transição entre o nível micro e macroeconômico e de como se desenvolvem os efeitos de retroalimentação entre eles.

\section{Possibilidades de avanço na discussão da complexidade da economia a partir da integração analítica da micro e da macroeconomia}

A presente seção, a partir da perspectiva crítica ao paradigma neoclássico apresentada na seção anterior, destaca algumas fundamentações teóricas alternativas às do paradigma dominante, à luz de autores e abordagens críticas ao referido paradigma. Busca-se, desse modo, por meio de um exercício analítico-sintético, apontar possíveis direções para a formação de novos paradigmas que lidem adequadamente com o caráter complexo da Economia, partindo de parte da própria literatura crítica ao mainstream.

\subsection{Enquadramento teórico-metodológico: sugestão de requisitos para lidar com a complexidade da economia}

Na seção 1.2, sugeriu-se que a abordagem da complexidade acrescenta poder explicativo à ciência econômica justamente porque parte da concepção do sistema econômico como dinâmico, adaptativo e complexo, trazendo, para dentro do escopo analítico da Economia, a necessidade de lidar com essas características. Estas, uma vez admitidas, carregam consigo o imperativo de um aparato teórico-metodológico que permita um enfoque dinâmico, não linear e não determinista. Condições que não 
são satisfeitas pela perspectiva teórica do mainstream, baseada nos pressupostos da maximização e do equilíbrio. $\mathrm{O}$ abandono desses pressupostos permite uma maior riqueza analítica na medida em que torna interessantes fatores e características pouco discutidos pelo enfoque convencional, por terem sido considerados pouco relevantes para entender e prever o funcionamento da economia. Dentre as limitações que o aparato teórico-metodológico deste enfoque implica, podem ser citadas:

(i) ao partirem das hipóteses de que os agentes detêm racionalidade perfeita, de que as informações estão disponíveis ou são redutíveis a distribuições de probabilidades, não há empecilhos para que estes tomem decisões otimizadoras. Define-se o agente representativo - os agentes são homogêneos ou não diferem de forma essencial da média - como racional-maximizador ${ }^{13}$, estabelecendo, a priori, qual será a sua decisão;

(ii) a definição de concorrência perfeita, que é o ideal teórico e normativo da concorrência, limita esta a preços, que compatibilizam, perfeitamente, a maximização de utilidade ou de lucro dos agentes, resultando em ótimos sociais;

(iii) não há mecanismo endógeno de mudança, - pelo contrário, há forças endógenas que mantêm a estabilidade - portanto, as mudanças são explicáveis somente por fatores exógenos;

(iv) presença de estabilidade estrutural, sendo a estrutura do sistema, por conseguinte, imune à sua própria dinâmica;

(v) a análise baseada no equilíbrio determina a priori quais são as condições - englobadas por (i) a (iv) - para que ele seja verificado. O foco está, portanto, sobre o resultado e não sobre o processo - ou sobre o poder de previsão, mais do que sobre o poder explicativo;

(vi) definição da macroeconomia como "agregação da microeconomia", permitida por condições restritivas impostas no contexto da teoria do consumidor e da teoria da firma, o que ocasiona, na prática, uma separação analítica, especialmente do ponto de vista dinâmico, da micro e da macroeconomia.

Por meio da superação das limitações analíticas impostas pelos pressupostos fundadores do mainstream econômico, potencialmente abre-se espaço para:

(i)' a discussão de como os limites cognitivos e informacionais dos agentes impactam suas decisões, bem como a consideração de sua heterogeneidade, deixando em aberto uma maior possibilidade de comportamentos racionais dos agentes, são importantes para entender tanto a própria relação interativa dos

(13) Como bem observa Zamagni (1993, p. 31), “[M]arginalism offers a special version of the utilitarian vision in which human behaviour consists exclusively in rational calculation aimed at utility maximization. This principle is recognized as having universal validity; alone it was able to explain the role economic reality" (Ênfase adicionada). 
agentes quanto para uma maior apreensão de detalhes sobre a dinâmica do sistema, auxiliando na identificação de propriedades micro e macrodinâmicas;

(ii)' uma definição mais ampla para o conceito de concorrência, e dessa forma para o conceito de competitividade, identificando na lógica de funcionamento dos mercados fontes tanto estimuladoras como apaziguadoras de efeitos desencadeados em determinado âmbito do sistema;

(iii)' a endogeneização das mudanças, destacando o caráter - mesmo que apenas em potencial - instável do sistema econômico capitalista, e também a capacidade de adaptação e aprendizado de seus agentes;

(iv)' a ocorrência de mudanças estruturais, jogando luz ao caráter adaptativo e evolucionário do sistema;

(v)' aumentar o escopo analítico, subordinando o(s) resultados(s) de determinado processo às condições em que se desenrola, e ao focalizar o processo, incrementar o poder explicativo da teoria;

(vi)' investigar a interação entre os agentes no campo microeconômico, a transição do campo micro para o campo macroeconômico, a relação entre os agentes e o sistema econômico - o feedback entre os níveis micro e macroeconômico -, permitindo e tornando interessante uma integração analítica dinâmica da micro e da macroeconomia.

Elencadas algumas das possibilidades de avanço na discussão da dinâmica da economia deixadas em aberto pela substituição de uma análise baseada nos pressupostos de equilíbrio e da maximização, sugere-se que, para que essas questões sejam satisfatoriamente discutidas, o aparato teórico-metodológico que a norteia deve apresentar as seguintes características: (i) uma microfundamentação adequada a sistemas complexos; (ii) mecanismos que fundamentem a interação entre os agentes; (iii) mecanismos que expliquem como transcorre a passagem do que ocorre no campo "micro" para o que ocorre no campo "macro"; (iv) mecanismos que expliquem as relações de feedback entre a micro e a macroeconomia; e que possua, portanto, (v) um enfoque dinâmico, não linear e não determinista.

Essas condições podem ser, em boa medida, satisfeitas por uma abordagem que permita a integração analítica, sob uma perspectiva dinâmica e complexa, da micro e da macroeconomia, como argumentado na próxima subseção.

\subsection{As potenciais contribuições teórico-metodológicas de uma abordagem micromacrodinâmica para o incremento do poder explicativo da Ciência Econômica}

O objeto geral de investigação da Economia, obviamente, é o próprio funcionamento do sistema econômico. Desse modo, seja qual for o corte teórico 
realizado para investigar determinada engrenagem da economia, não parece ser uma escolha apropriada desconsiderar ou distorcer aquelas que são as suas características nucleares. Nesse sentido, argumenta-se que uma abordagem que permite discutir adequadamente questões abrangentes, como as relativas às flutuações, ao progresso tecnológico e ao desenvolvimento, e a tantos outros fenômenos econômicos que conjugam uma série de fatores e condicionantes, das mais diversas naturezas, é aquela que possibilita uma análise integrada, e sob uma perspectiva dinâmica e complexa, dos níveis micro e macroeconômico.

Em linhas gerais, enquanto sistema, a economia compõe-se por agentes idiossincráticos com potencial de aprendizado e adaptação, cujas interações são coordenadas por normas, instituições e organizações endógenas. Não há nenhum mecanismo global de controle, mas pode apresentar mecanismos de autoorganização e estruturas emergentes que resultam tanto da interação de seus agentes, quanto destes com o ambiente. O novo emerge recorrentemente, atribuindo-lhe variadas fontes de instabilidade dinâmica e estrutural, desencadeando um permanente processo de adaptação e renovação.

São também de interesse direto da análise econômica as diversas esferas que compõem o sistema econômico. Grosso modo, da esfera alocativa derivam questões sobre como os agentes realizam decisões referentes ao consumo e ao seu portfólio. A partir da esfera produtiva, questiona-se quanto e como os agentes produzem e como realizam seus planos de investimento. A esfera financeira, enquanto complementar e concorrente à esfera produtiva, levanta questões sobre, respectivamente, a disponibilidade de recursos financeiros para os agentes realizarem seus planos e as decisões de portfólio. Por fim, da esfera distributiva insurgem questões relativas à divisão dos recursos entre os agentes, bem como de suas consequências dinâmicas. Tomadas juntas, as características e condições presentes em cada uma dessas esferas geram e realimentam a própria dinâmica que desencadeiam.

Posta a relação sistêmica entre os agentes e o ambiente em que agem, tornase potencialmente desinteressante do ponto de vista explicativo, tanto uma separação artificial do que é considerado de interesse da microeconomia ou da macroeconomia, quanto a imposição de condições restritivas, de tal forma que o âmbito macroeconômico possa ser analisado simplesmente como um somatório horizontal das condições presentes no nível micro, desconsiderando a possibilidade de emergência - por conta da natureza das características de seus agentes e da própria dinâmica do sistema econômico -, de propriedades e fenômenos novos ou emergentes.

A impossibilidade de exercício ilimitado da racionalidade econômica implica a diversidade comportamental dos agentes, não apenas por serem eles 
mesmos heterogêneos, mas pela falta de elementos objetivos (incerteza substantiva) e pelas limitações cognitivas (incerteza procedimental). A diversidade comportamental dos agentes por si só adiciona elementos extras à incerteza. E, se os agentes já são diversos, a própria concorrência capitalista enseja a geração de mais diversidade que, por isso, possui caráter endógeno. Assim, diferente de equilíbrio e estabilidade estrutural, o que se observa no sistema econômico são mudanças frequentes nos parâmetros estruturais e expectacionais e uma geração constante de diversidade - em diversos aspectos, desde os comportamentais até os institucionais.

No entanto, mesmo caracterizado por instabilidades, podem surgir regularidades comportamentais no sistema econômico justamente por meio, por exemplo, da tentativa dos agentes em reduzir essas instabilidades e, por conseguinte, em aumentar o grau de previsibilidade do futuro. Dito de outra forma, regularidades comportamentais podem surgir por conta da própria incerteza característica do sistema. ${ }^{14} \mathrm{O}$ que é bem diferente de dizer que, como os comportamentos dos agentes são regulares - ou previsíveis -, o sistema é equilibrado, ou que, como o sistema é efetivamente estável, os comportamentos são regulares. Outras fontes potenciais de estabilidade podem ser encontradas nos próprios mecanismos cumulativos endógenos, especialmente na medida em que implicam dependência de trajetória, que pode vir a aprisionar o sistema em determinados limites.

Segue-se que a grande vantagem aparente, em termos teóricometodológicos, do enfoque micromacrodinâmico complexo aqui sugerido como mais fecundo é não limitar artificialmente o escopo de investigação da economia. Diferentemente de um enfoque baseado na definição de indivíduos super-racionais e delimitado por análises de (tendência ao) equilíbrio, uma abordagem micromacrodinâmica complexa que satisfaça os requisitos (i) a (v) listados na seção 2.1 admite implicações dinâmicas permanentes e cumulativas da presença de desequilíbrios que originam, estimulam e disseminam impulsos microeconômicos, levando a outros mecanismos desestabilizadores, resultando na instabilidade dinâmica e estrutural do sistema, que provoca mais mudanças e desequilíbrios, e assim sucessivamente. Entretanto, apesar de seu caráter mutante e instável, o sistema econômico capitalista não é caótico, o que remete ao questionamento de como ocorre a sua organização. Paradoxalmente, a resposta parece estar nos próprios mecanismos endógenos que ensejam a ocorrência de mudanças e o estado potencial de instabilidade.

Assim sendo, um caminho apropriado para apreender as particularidades da dinâmica do sistema capitalista, tanto no que se refere, parafraseando Keynes, à sua instabilidade potencial quanto à sua estabilidade efetiva, parece ser, em primeiro lugar, o da integração analítica dinâmica da micro e da macroeconomia e, em

(14) Por exemplo, o comportamento convencional (Keynes, 1936) e as rotinas (Nelson; Winter, 1982). 
segundo lugar, da consideração das características nucleares do sistema econômico, de tal forma que permitam a investigação conjunta dos efeitos dinâmicos e resultados não lineares impulsionados pelos níveis micro e macroeconômico, organicamente interligados e, por isso, geradores da complexidade do sistema.

\subsection{Keynes, Kalecki, Schumpeter, Simon e abordagem da complexidade: elementos para uma síntese analítica micro-macro e complexa}

Nesta subseção, são indicados alguns elementos teóricos, pertinentes a uma abordagem micromacrodinâmica complexa, que vêm ao encontro da satisfação dos seguintes requisitos (i) a (v). Concomitantemente, realizam-se considerações sobre a estrutura teórica de modelos macroeconômicos representativos do mainstream, desde modelos mais simples, como o de Solow, até os mais sofisticados e recentes, como os modelos de equilíbrio geral dinâmicos e estocásticos - ou modelos DSGE -, que compõem o novo consenso macroeconômico ou a nova síntese neoclássica ${ }^{15}$.

\section{(i) Microfundamentação adequada a um sistema complexo}

Microfundamentar adequadamente modelos teórico-analíticos em Economia é um requisito crucial para a compreensão da sua dinâmica. Especialmente para um enfoque que pretende integrar analiticamente a micro e a macroeconomia, sem entender o comportamento e o processo decisório dos agentes não há como identificar os efeitos microdinâmicos provocados, por exemplo, por determinadas políticas, mudanças estruturais ou choques de quaisquer naturezas.

A discussão sobre a importância de microfundamentar modelos macroeconômicos não só está presente no mainstream, mas pode-se dizer que se originou dele. Antes mesmo da crítica de Lucas $^{16}$, algumas tentativas no sentido de introduzir aspectos microeconômicos em modelos macro foram realizadas. Um bom exemplo é o modelo de Ramsey, que se assemelha estruturalmente ao modelo de Solow, mas no qual a dinâmica da economia agregada é supostamente determinada por decisões no nível microeconômico. A evolução do estoque de capital é derivada da interação, em mercados competitivos, de firmas e indivíduos maximizadores. Define-se uma função de utilidade, cuja maximização condiciona-se a uma restrição orçamentária. No entanto, mesmo com a taxa de acumulação de capital sendo endógena, os resultados para a taxa de crescimento de equilíbrio são tão limitados

(15) Por exemplo, vide Woodford (2003) e Gali (2008).

(16) A crítica de Lucas aponta para a relevância das expectativas. Como resultado, mudanças nas políticas podem alterar relações agregadas. Todavia, sob a hipótese de expectativas racionais, somente choques de demanda não observados têm efeitos reais e políticas monetárias só terão efeitos reais apenas se os agentes privados não tiverem acesso a algumas informações - ou seja, se houver informação imperfeita. Em outras palavras, comparativamente à abordagem de expectativas de Keynes, pode-se dizer que as expectativas racionais reduzem o problema da incerteza a um problema de informação imperfeita. 
como as do modelo de Solow, dependentes de fatores exógenos ao processo decisório dos agentes.

Representando uma extensão - com algumas modificações - do modelo de Ramsey, os modelos de ciclos reais de negócios são microfundamentados com base na hipótese de expectativas racionais, na característica maximizadora intertemporal de seus agentes e são integralmente walrasianos ${ }^{17}$. Consequentemente, qualquer choque - ou instabilidade - que aconteça na economia tem origem exógena e seus efeitos são naturalmente acomodados pelas reações maximizadoras dos agentes, pautadas em expectativas racionais.

Os modelos macroeconômicos novo-keynesianos, que estruturalmente diferem muito pouco dos modelos de ciclo reais de negócios, são microfundamentados no mesmo sentido desses últimos: os agentes possuem comportamento maximizador intertemporal e pautam-se em expectativas racionais. Mesmo com a introdução de considerações a respeito das imperfeições dos mercados, o que torna o ajustamento nominal mais lento e imperfeito, também nos modelos novo-keynesianos, pós-choques, a economia sempre volta à sua taxa de crescimento natural, que depende exclusivamente de fatores de oferta.

Os modelos DSGE são representativos do novo consenso macroeconômico, que resulta da combinação da abordagem de equilíbrio geral dinâmico dos modelos de ciclos reais de negócios com as rigidezes e imperfeições de mercado dos modelos novo-keynesianos. Nos modelos DSGE, os agentes resolvem problemas de otimização intertemporais, sendo os seus elementos um continuum de indivíduos e firmas idênticas, que consomem e produzem um continuum de bens. Essas hipóteses não apenas permitem trabalhar com um indivíduo e firma representativa em um equilíbrio simétrico, mas fazem com que, em tal equilíbrio, as variáveis agregadas igualem a sua média e valores unitários ${ }^{18}$. Como resultado geral desse modelo, os choques são acomodados e, sem grandes novidades com relação ao resultado dos outros modelos do mainstream, retorna-se ao equilíbrio. ${ }^{19}$

Segue-se que a natureza da microfundamentação proposta pelos modelos mainstream continua não contribuindo analiticamente, nem do ponto de vista macroeconômico, nem do ponto de vista dinâmico e muito menos do ponto de vista da interação micro-macro, para compreender o processo decisório dos agentes, a

(17) Agentes homogêneos e tomadores de preços em concorrência perfeita.

(18) Vide Duarte (2011).

(19) Sobre esse ponto, vale destacar observação de Colander et al.: "[a]s economists such as Pareto, Hicks, and Koopmans have made clear, the assumptions we make about individuals in microeconomics are based on introspection, not on any mass of coherent empirical evidence or even on any intuitive plausibility criteria. The only justification of the hyper-rational self-interested agent typically used in standard macro models was that it was consistent with the characterization used in micro theorizing. And even that justification is disappearing with the rise of behavioral economics" (2008, p. 236). 
interação entre os agentes e a transição entre os níveis. A recorrência às expectativas racionais apenas reforça e sofistica as limitações impostas pela homogeneidade e comportamento maximizador dos agentes. Ao limitar o processo decisório dos agentes simplesmente a um problema de maximização intertemporal, o sistema poderá mais facilmente tender ao equilíbrio sob hipóteses restritivas adicionais relativas às funções de produção, garantidas de partida pela estrutura teórica desses modelos e não por alguma preocupação específica de aderência a processos reais. ${ }^{20}$ Como bem observado por Colander et al., as escolhas teóricas apropriadas não podem ser determinadas a priori e sim devem ser feitas com referência a dados empíricos de modo que possam levar a modelos macroeconômicos úteis, o que não foi nem tem sido realizado pela abordagem mainstream, na medida em que essa se mantém atrelada a microfundamentos baseados em agentes representativos altamente racionais (2008, p. 236).

De maneira distinta, a microfundamentação aqui apontada como adequada a sistemas complexos, deve abraçar as seguintes questões: dada a incerteza, a impossibilidade de exercício de racionalidade substantiva por parte dos agentes econômicos (Simon), o seu processo de formação de expectativas (Keynes), assimetrias tanto entre as firmas quanto entre os indivíduos, abarcando um maior grau de heterogeneidade (Kalecki, abordagem da complexidade e neoschumpeterianos). Fica em aberto, dessa forma, a análise de uma diversidade de comportamentos racionais possíveis, bem como da natureza e propriedades da dinâmica que pode emergir da interação entre esses agentes.

As contribuições teóricas citadas no parágrafo anterior, se tomadas conjuntamente, sugerem alguns passos para a construção de uma microfundamentação adequada a sistemas dinâmicos e complexos. Em contraste com a hipótese de homogeneidade, o sistema econômico capitalista é caracterizado por uma grande heterogeneidade dos seus agentes, que perpassa questões, a princípio, tratáveis ao instrumental econômico, como as definições de classes de renda e de estratégias empresariais. Levar analiticamente em conta essas questões permitiria uma investigação mais detalhada tanto da intensidade quanto da natureza de efeitos micro e macrodinâmicos.

Comparativamente à microfundamentação baseada na hipótese de expectativas racionais e na definição de agente representativo maximizador, as características das soluções que emergem dos processos interativos do sistema

(20) Partindo da hipótese de que os fatores de produção são remunerados pela sua produtividade marginal, é possível construir modelos macroeconômicos walrasianos nos quais os valores dessas remunerações existam de tal forma que o nível dos fatores de produção empregados sejam de pleno emprego. Caso o nível dos fatores de produção se altere, as suas remunerações serão ajustadas até que se atinja o market clearing. Em outras palavras, é suficiente impor restrições matemáticas na função de produção e, ocasionalmente, nas descrições do sistema macroeconômico, para assegurar o pleno emprego dos fatores (Taylor, 2004, p. 11). 
econômico a partir de uma microfundamentação adequada a sistemas complexos não estão pré-definidas, pois não há apenas um comportamento racional possível - como o maximizador, definido sob condições bastante restritivas. A diversidade potencial de comportamentos racionais implica, por sua vez, imprevisibilidade e mais incerteza, sendo esta também consequência dos próprios agentes do sistema. ${ }^{21}$

Assim, por meio da discussão da capacidade dos agentes em lidar com a complexidade do sistema econômico, o foco sai do resultado e se dirige ao processo decisório propriamente dito. E é focalizando no processo decisório em um ambiente caracterizado por incerteza fundamental que deve ser buscada, na medida do possível, a riqueza de detalhamentos por parte da microfundamentação, a fim de incrementar o poder explicativo da teoria.

\section{(ii) Explicação da dinâmica de interação entre os agentes}

Em consonância com as considerações feitas no item anterior, o cumprimento do requisito (i) permite um embasamento mais sólido da explicação da dinâmica de interação entre os agentes, considerada de suma importância para a identificação, de efeitos microdinâmicos e de propriedades macroemergentes. Da mesma forma, a microfundamentação proposta pelos modelos mainstream possuiria, teoricamente, o mesmo objetivo, mas com a seguinte qualificação: incrementar o entendimento da "dinâmica" da trajetória de convergência ao equilíbrio.

No entanto, como argumentado no item anterior, a microfundamentação baseada em expectativas racionais apenas reforça as limitações analíticas já impostas pelo agente representativo maximizador. A dinâmica que emerge dessa estrutura teórica é um processo de convergência a um resultado pré-determinado, ${ }^{22}$ o chamado equilíbrio competitivo, o qual pode ser definido exclusivamente a partir das condições de oferta. Fundamental ao alcance desse resultado é a hipótese de concorrência perfeita implícita em boa parte dos modelos mainstream, que atribui ao processo de concorrência um caráter apenas passivo, de ajustamento a parâmetros pré-determinados. No caso dos modelos que, em alguma medida, incorporam imperfeições de mercado, no entanto, vale notar que a imperfeição dos mercados só vem a implicar um ajuste mais lento rumo ao equilíbrio.

Conforme observação de Colander et al., uma abordagem macroeconômica mais razoável deve levar em consideração que o comportamento do agregado não necessariamente corresponde ao comportamento de seus componentes e que, por

(21) Por exemplo, contrariamente ao comportamento do tipo convencional sugerido por Keynes, o comportamento do tipo inovador definido por Schumpeter destoa do comportamento médio, sendo uma fonte potencial importante de mais incerteza para o sistema econômico capitalista.

(22) Paradoxalmente, para Keynes, a principal fonte de interação dinâmica entre os agentes econômicos é o próprio processo de formação de expectativas. Ao invés de as expectativas gerarem estabilidade, a característica volátil das expectativas dos agentes é uma fonte poderosa de instabilidade dinâmica do sistema econômico. 
conseguinte, não se podem extrair conclusões agregadas a partir de um agente representativo. Nesse sentido, os modelos macroeconômicos que se pretendem explicativos devem analisar não apenas as características dos indivíduos mas também a estrutura de suas interações (Colander et al., 2008, p. 236-237).

Para que a interação dos agentes seja satisfatoriamente investigada, bem como as propriedades que dela emergem, sugere-se que devem ser considerados: o caráter volátil das expectativas (Keynes), as relações dinâmicas entre as classes e entre os setores produtivos (Kalecki), um enfoque dinâmico sobre a concorrência (Schumpeter), a importância dos fatores sistêmicos (neoschumpeterianos) e a coordenação das interações entre os agentes por normas e instituições (abordagem da complexidade) $)^{23}$.

Essas contribuições teóricas constituem desse modo, uma explicação da dinâmica de interação dos agentes oposta àquela do mainstream, baseada na qual os agentes, teoricamente, não necessitam levar em conta a existência de outros agentes, uma vez que são representativos. O processo de formação de expectativas, em meio à incerteza, representa um mecanismo pelo qual os agentes, no processo decisório, levam tanto em consideração a existência de outros agentes, permitindo a construção de uma explicação dinâmica dessa interação, quanto os constrangimentos e restrições institucionais impostos pelo sistema. Nesse sentido, as expectativas à la Keynes desempenham tanto o papel de guia de decisão como de passaporte temporal para o futuro - embora não de bola de cristal, como no caso das expectativas racionais.

Trazer para dentro do escopo de interesse da teoria a heterogeneidade dos agentes, com assimetrias de diversas naturezas, invalida a configuração ideal do processo de concorrência perfeita, coordenado eficientemente pelo mecanismo de preços. A própria dinâmica da concorrência capitalista enseja a geração de mais diversidade e heterogeneidade, afastando da hipótese de agentes representativos e homogêneos, crucial para a definição de concorrência perfeita. Levanta-se a necessidade de compreensão de como são desenhadas, por exemplo, as estratégias de concorrência das empresas, que dependem também das características do mercado em que atuam, e da própria interdependência entre os mercados, o que representa uma importante fonte tanto de restrições adicionais quanto de potencialização de efeitos iniciados em determinado setor.

Assim como argumentado para o item (i), as contribuições teóricas na linha micro-macro, listadas acima, tomadas em conjunto, embora acrescentem poder explicativo à dinâmica de interação entre os agentes, também implicam a necessidade de consideráveis avanços. Estes apontam, por exemplo, para o desenvolvimento de uma teoria de formação de expectativas mais complexa que as do tipo adaptativas - embora, em larga medida, estas se mostrem dinamicamente

(23) E, embora não tenha sido aqui abordada, a teoria institucionalista. 
mais interessantes do que as do tipo racional. Ademais, o reconhecimento do caráter dinâmico e imperfeito da concorrência deixa em aberto a necessidade de estruturas teóricas específicas ${ }^{24}$ para o avanço tanto no que se refere ao entendimento da dinâmica da concorrência intrassetores, quanto da dinâmica entre setores, fundamentais para o reconhecimento dos decorrentes efeitos micro e macrodinâmicos, potencialmente embasando a definição de políticas macroeconômicas, industriais e tecnológica com maiores chances de sucesso.

\section{(iii) Explicação da dinâmica de transição entre os níveis micro e macroeconômico}

As discussões aventadas em (i) e (ii) também permitem uma percepção mais detalhada da dinâmica de transição entre os níveis micro e macroeconômico, considerada crucial no processo de identificação da emergência de propriedades micro e macrodinâmicas.

À exceção dos modelos mais recentes - especialmente aqueles que consideram imperfeições de mercado -, a estrutura teórica dos modelos representativos do mainstream apresenta como premissa a concorrência perfeita, o que implica que o mecanismo de preços desempenha plenamente o seu papel de estabilizador natural do sistema, levando-o sempre ao equilíbrio. Porém, todos os modelos representativos do mainstream, sem exceção, estão pautados por análises de equilíbrio, mesmo que apenas no longo prazo. Por outro lado, uma abordagem pautada pela presença de incerteza fundamental e pelo caráter dinâmico da concorrência atribuiria a esta também o papel de desestabilizadora, explicando, endogenamente, as mudanças do sistema.

$\mathrm{Na}$ tentativa de explicar endogenamente o crescimento, o que idealmente representaria uma evolução relativamente aos modelos mais simples como os de Solow, os modelos de crescimento endógeno o fazem por meio, por exemplo, da incorporação do progresso técnico - via aprendizado. Esses modelos tratam a acumulação de capital da mesma forma que o modelo de Solow, mas diferem ao interpretar o trabalho efetivo explicitamente como conhecimento e ao modelar sua evolução temporal. Introduz-se no modelo um setor de $\mathrm{P} \& \mathrm{D}$, produtor de novas tecnologias. Assume-se uma função de produção na qual trabalho (L), capital (K) e tecnologia (A) são combinados de forma a levar a melhorias na tecnologia ${ }^{25}$. A endogeneização desses modelos é alcançada pela hipótese de rendimentos crescentes do conhecimento, embora os rendimentos da produção de conhecimento (e dos demais fatores de produção) sejam decrescentes. Segue-se que a acumulação de conhecimento é definida como endógena. Porém os resultados continuam ignorando

(24) Levando em consideração fatores como: restrição financeira, utilização da capacidade produtiva, estratégias competitivas, horizonte de planejamento, intensidade da concorrência, padrão distributivo e encadeamentos produtivos.

(25) Para mais detalhes, vide Romer (2006). 
o papel determinante da acumulação de capital sobre a taxa de crescimento, devido aos rendimentos decrescentes do capital, e se assemelham, nesse sentido, aos do modelo de Solow. As mudanças na estrutura desses modelos, comparativamente aos neoclássicos originais, são marginais, não alterando nenhum dos pressupostos principais, em especial o de maximização e de convergência ao equilíbrio.

Modelos de ciclos econômicos novo-clássicos sugerem uma forma de reconciliar flutuações no nível de emprego com a noção de equilíbrio geral walrasiano. Os primeiros modelos atribuem à informação incompleta sobre a oferta monetária agregada à principal causa das flutuações, o que os aproxima, em larga medida, da abordagem monetarista. Todavia, a explicação da ligação entre a variabilidade da oferta de moeda e os ciclos é distinta, pois a análise novo-clássica parte de microfundamentos - vale dizer, inadequados do ponto de vista da interação micro-macro.

Os modelos de ciclos econômicos reais, por sua vez, se distanciam da abordagem monetarista e dos primeiros modelos de ciclos de tradição novo-clássica, pois se assume que variáveis nominais não explicam, em nenhuma medida, os ciclos de negócios. Com o intuito de investigar as flutuações agregadas estes modelos representam uma extensão do modelo de Ramsey ${ }^{26}$, modificado em dois sentidos: (i) inclusão de fontes de distúrbios reais - por exemplo, choques tecnológicos ${ }^{27} \mathrm{e}$ (ii) permissão de variações endógenas no emprego - via inclusão das horas trabalhadas na função de utilidade dos trabalhadores, implicando uma alocação intertemporal entre trabalho e lazer. Os ciclos, sob essa abordagem, apenas refletem as decisões maximizadoras dos agentes em resposta aos choques reais. A hipótese de mercados competitivos e a modelagem dos ciclos como um fenômeno de equilíbrio presentes nesses modelos retira, por exemplo, qualquer papel de estabilização de políticas macroeconômicas (Carlin; Soskice, 2006).

Sob a perspectiva novo-keynesiana, as imperfeições nominais - por exemplo, custos de menu - são importantes para flutuações na atividade agregada. Os modelos macroeconômicos novo-keynesianos consideram que os preços e salários podem ser imperfeitamente flexíveis, associados a imperfeições no mercado de trabalho e/ou mercado produtivo. Comparativamente aos modelos de ciclos reais de negócios, os novos-keynesianos modelam os ciclos como fenômenos de desequilíbrio, tornando o produto real e o emprego como variáveis de ajuste a mudanças no produto agregado nominal.

Em modelos novo-keynesianos mais recentes, destaca-se o banco central como forward looking, o qual desempenha a função de guiar a economia novamente

(26) Segundo Romer (2006), representa a base walrasiana para economia agregada: exclui não apenas as imperfeições de mercado, mas todas as questões que se referem à heterogeneidade entre os agentes.

(27) Na verdade, choques de produtividade. 
ao equilíbrio, reagindo a qualquer choque ${ }^{28}$, por meio de uma função de reação prédeterminada $^{29}$. A economia sempre volta à sua taxa de crescimento natural, que depende exclusivamente de fatores de oferta, embora, paradoxalmente, seja essa uma abordagem com keynesiano em seu nome. Segue-se que as políticas macroeconômicas continuam não tendo efeito sobre as variáveis reais no longo prazo. Mesmo com a introdução de considerações a respeito das imperfeições dos mercados, os modelos novo-keynesianos não se afastam, em nenhum grau, das premissas de comportamento maximizador e de equilíbrio, e se mostram igualmente centrados na oferta agregada, o que os coloca na mesma linha de críticas feitas aos outros modelos macroeconômicos do mainstream (todos essencialmente de tipo "supply side", em clara oposição a Kalecki e aos neokeynesianos) ${ }^{30}$.

Quanto aos modelos DSGE, como bem destaca Colander et al., embora eles parecem extremamente complicados, é na sua sofisticação matemática e não no modelo em si que se encontra a sua dificuldade. Esses modelos não avançam na direção de complicadores analíticos tais como heterogeneidade dos agentes, dinâmica estatística, equilíbrios múltiplos ou ausência de equilíbrio e aprendizado endógeno, os quais apresentariam implicações dinâmicas importantes para capturar e explicar questões importantes no nível macroeconômico (2008, p. 238).

Sugere-se que, para uma explicação satisfatória da dinâmica de transição dos níveis micro e macroeconômico, se mostram mais interessantes os seguintes elementos: um princípio de causalidade condizente com a economia capitalista como economia monetária, como o princípio da demanda efetiva (Keynes, Kalecki); componentes de flutuação $\left(\right.$ Keynes $^{31}, \mathrm{Kalecki}^{32}$ ); caráter imperfeito da concorrência, distribuição de renda e uma abordagem multissetorial (Kalecki); um enfoque dinâmico sobre a concorrência e sobre a criação endógena de diversidade (Schumpeter e neoschumpeterianos); ausência de mecanismo global que controle a

(28) Aliás, vale destacar que, como nos outros modelos macroeconômicos do mainstream, a questão do investimento, central a qualquer abordagem genuinamente keynesiana, no máximo, serve para explicar choques.

(29) Por exemplo, uma regra de taxa de juros, $r=r 0+\alpha(\pi-\pi \mathrm{T})$, onde $\mathrm{r}$ é a taxa de juros real e $\pi \mathrm{T}$ é a meta de inflação (Lavoie, 2004).

(30) Das restrições impostas à função de produção, segue-se que a oferta de recursos financeiros é também determinada pelas fórmulas de produtividade marginal e de pleno emprego. Todavia, se a taxa de acumulação é fixa, não há espaço para o sistema determinar, independentemente, o nível de investimento. Daí uma das fontes de incompatibilidade lógica de abordagens do tipo supply-side e daquelas baseadas no princípio da demanda efetiva. Em uma estrutura keynesiana-kaleckiana, a maneira de estimular a produção e o crescimento é via, principalmente, acréscimos no investimento. Quedas na demanda por consumo - ou o aumento da propensão a poupar - podem mesmo ter efeitos negativos sobre a produção (Taylor, 2004, p. 11). Vide, por exemplo, o paradoxo da parcimônia de Keynes.

(31) As variações na propensão a consumir e na preferência pela liquidez, que podem atenuar ou acentuar os ciclos econômicos; e a eficiência marginal do capital, que confere maior regularidade ao ciclo (Dweck, 2006).

(32) Os ciclos econômicos são explicados por meio dos efeitos dinâmicos do funcionamento do princípio da demanda efetiva, levando em consideração questões como restrições financeiras e grau de utilização da capacidade produtiva. 
interação entre os agentes e entre os agentes e o ambiente econômico ${ }^{33}$ (abordagem da complexidade).

Diferentemente de uma abordagem centrada no equilíbrio de todos e cada mercado, nada garante que a demanda seja, ex post, igual à oferta. E, muito menos, que nas condições de oferta agregada residem todas as condições determinantes do sistema. A complexidade da dinâmica de transição entre os níveis micro e macroeconômico não é apreensível por meio de um enfoque determinista, equilibrista e agregativo.

O princípio da demanda efetiva, pelo contrário, seria compatível com um enfoque não determinista - pois não necessariamente pré-determina resultados, embora demarque a precedência lógica dos gastos sobre a renda, ou da demanda sobre a oferta; não equilibrista - pois os agentes sempre podem errar suas previsões a respeito da demanda futura; e não agregativo - pois, especialmente via expectativas $^{34}$, permite a consideração da interação entre os agentes e entre os agentes e o ambiente macroeconômico, sendo, dessa forma, passível de ser compatibilizado a um método de análise sistêmico (Prado, 2006). A dinâmica do mecanismo multiplicador da renda ilustra bem essas duas características: a duração temporal dos efeitos de indução desencadeados pelas decisões de gasto não é mensurável e, portanto, os resultados que geram sobre a renda não são definíveis $a$ priori, apenas uma ordem de grandeza de seus efeitos potenciais e sem prazo prédefinido.

Um enfoque sobre o caráter dinâmico da concorrência, de estimular e selecionar diversidades, extrapola a caracterização do mercado como apaziguador de diferenças e da existência de estabilizadores que automaticamente levam o sistema ao equilíbrio - como o sistema de preços. Não há, portanto, nenhum mecanismo global de controle, nem vias que guiem, rápida ou morosamente, o sistema a um estado dito de equilíbrio.

No entanto, apesar dos elementos teóricos na linha micro-macro permitirem avanços na explicação da dinâmica de transição entre os níveis micro e macroeconômico, há muito que avançar. Em especial, vale citar a importância da esfera financeira ${ }^{35}$ para compreender a dinâmica do capitalismo contemporâneo. Na busca de um maior poder explicativo, sua análise deve ser integrada mais

(33) Não obstante, os sistemas complexos podem apresentar mecanismos de auto-organização e propriedades emergentes resultantes dessas interações.

(34) Embora o método "agregativo" não seja incompatível com expectativas, lembrando que o próprio Keynes trabalha com simplificações agregativas.

(35) As restrições financeiras ao investimento são previamente discutidas por Kalecki, e, especialmente, explorada por Minsky, embora. Ver, por exemplo, Minsky (1982). 
detalhadamente $^{36}$ às das esferas produtiva e distributiva ${ }^{37}$, a fim de apreender os resultados macrodinâmicos ocasionados por determinados parâmetros e aspectos financeiros, produtivos e distributivos ${ }^{38}$.

\section{(iv) Explicação das relações de feedback entre os níveis micro e macroeconômico}

Se a estrutura teórica dos modelos representativos do mainstream não comporta apropriadamente, do ponto de vista micro-macrodinâmico, as discussões dos itens (i) a (iii), contribuem ainda menos para explicar as relações de feedback entre os níveis micro e macroeconômico. Apesar das tentativas de consideração de questões microeconômicas nesses modelos, ou até da consideração de imperfeições de mercados, as premissas de comportamento maximizador e de equilíbrio são integralmente mantidas, o que torna mecânica, auto-reflexiva e previsível qualquer consideração sobre as relações de feedback entre os níveis micro e macro. Ademais, a explicação das mudanças no sistema não é determinada endogenamente, e mesmo os efeitos reais de choques exógenos são, no máximo no longo prazo, totalmente dissipados.

Esta última observação é especialmente importante para o progresso tecnológico que, por conta do seu caráter cumulativo, é um fator endógeno do crescimento econômico. Para o entendimento dos efeitos dinâmicos não lineares das inovações associadas ao progresso tecnológico, faz-se necessária uma abordagem que abarque a complexidade de fatores envolvidos nas decisões de investir em inovações, que podem se referir: à própria natureza da inovação; à formação de expectativas; às restriçõos propriamente ditas, como as de capital e financeira; e à maneira como se desenrola o processo de difusão e seleção de inovações pelo mercado - o qual, vale enfatizar, não necessariamente seleciona aquelas técnicas produtivas ou produtos mais "eficientes" (por exemplo, possibilidade de lock in).

Consideram-se como importantes elementos teóricos para compor uma explicação satisfatória das relações de feedback entre os níveis micro e macro: racionalidade do tipo procedimental (Simon), o caráter volátil do processo de

(36) Ou seja, não apenas via restrições financeiras representadas pelo risco de mercado ou pelo risco crescente, mas também como uma esfera que concorre, no processo de alocação de recursos, com a esfera produtiva, o que por sua vez pode ser influenciado por determinadas políticas macroeconômicas (por exemplo, políticas de metas monetárias).

(37) Como bem explicita Taylor (2004), por meio de canais distributivos, movimentos em preços "macro", como taxas de juros, taxa de câmbio e até salário mínimo, podem ter efeitos importantes sobre as possibilidades econômicas dos indivíduos e empresas.

(38) As instituições e as relações de distribuição entre os diversos setores produtivos e grupos sociais desempenham papel crucial na determinação de propriedades macroeconômicas. Estas considerações são levadas em conta, em algum grau, por abordagens heterodoxas como a pós-keynesiana, kaleckiana, neoricardiana e marxiana. 
formação expectativas $^{39}$ (Keynes), mecanismos endógenos de mudança (Keynes expectativas - e Schumpeter - inovações), uma abordagem multissetorial dinâmica (Kalecki, ainda que previamente), o caráter endógeno do processo de mudança estrutural (Schumpeter e neoschumpeterianos), mecanismos cumulativos (neoschumpeterianos e abordagem da complexidade) e método de análise sistêmico (abordagem da complexidade).

A combinação das contribuições teóricas citadas anteriormente, adicionalmente àquelas explicitadas nos itens (i) a (iii), permitem maior apreensão de algumas vias pelas quais se desenrolam as relações de feedback no sistema econômico e potencialmente adicionam poder explicativo e de identificação de propriedades emergentes. Os avanços remanescentes se referem tanto a aspectos teóricos propriamente ditos - como os destacados nos itens anteriores - quanto a aspectos operacionais, relacionados ao desenvolvimento de instrumental apropriado ao tratamento de sistemas complexos. Dado o grau de complicação envolvido, os modelos construídos sob essa base teórica envolvem, via simulações computacionais, o estudo das interações intra e entreníveis, com o objetivo de identificar mecanismos de auto-organização e a emergência de propriedades que não seriam apreensíveis sob uma perspectiva reducionista ${ }^{40}$, de caráter estático ou determinista. Assim como conclui Colander et al., "[I]f we are to develop newer, more encompassing macroeconomic theories, modern macroeconomists must expand their modeling repertoire, using all available analytic techniques and computational methods" (2008, p. 238).

\section{(v) Enfoque dinâmico, não-linear e não-determinista}

Conforme argumentado nos itens (i) a (iv), Simon, Keynes, Kalecki, Schumpeter e as abordagens pós-keynesiana, neoschumpeteriana e da complexidade fornecem elementos teóricos que permitem uma microfundamentação adequada a sistemas complexos, que explicam dinamicamente a interação entre os agentes, a transição entre os níveis micro e macroeconômico, bem como as relações de feedback que desenvolvem. Auxiliam, desse modo, na satisfação de requisitos necessários à construção de uma teoria que integre analiticamente a micro e macroeconomia, condições não satisfeitas por modelos representativos do mainstream e, em larga medida, por alguns modelos heterodoxos.

$\mathrm{Na}$ discussão dos requisitos anteriores já foram destacadas algumas contribuições teóricas que auxiliam na satisfação de (v). São eles:

(39) Sugere-se inclusive que o mecanismo de funcionamento do Princípio da Demanda Efetiva é um meio importante de transmissão de efeitos e mudanças entre os dois níveis, cujo passaporte temporal são as próprias expectativas.

(40) Cf. Prado (2006). 
(a) um enfoque dinâmico: expectativas e princípio da demanda efetiva (Keynes); abordagem multissetorial, distribuição de renda e teoria dos ciclos (Kalecki); concorrência dinâmica, interação dinâmica entre agentes e estruturas, endogeneidade das estruturas e de suas mudanças (Schumpeter e neoschumpeterianos).

(b) um enfoque não linear: racionalidade procedimental (Simon); expectativas (Keynes); teoria dos ciclos (Kalecki); aspectos sistêmicos e aspectos cumulativos do progresso técnico (Schumpeter e neoschumpeterianos); trajetórias em aberto, mecanismos cumulativos e método sistêmico (abordagem da complexidade).

(c) um enfoque não determinista: racionalidade procedimental (Simon); expectativas e princípio da demanda efetiva (Keynes); aspectos cumulativos do progresso técnico (Schumpeter e neoschumpeterianos); trajetórias em aberto, mecanismos cumulativos e método sistêmico (abordagem da complexidade).

Os elementos destacados nos itens (i) a (v) compõem, portanto, um conjunto teórico-metodológico que se mostra pertinente à construção de um enfoque complexo que integre dinamicamente a micro e a macroeconomia e, seguindo a linha de argumentação do presente trabalho, mais adequado para lidar com a complexidade do sistema econômico capitalista.

\section{Considerações finais}

Por meio de um esforço de síntese de algumas contribuições alternativas ao mainstream, nas quais podem ser encontrados elementos que fundamentem teórica e metodologicamente a integração dinâmica da micro e da macroeconomia e que não desconsideram o caráter dinâmico, adaptativo e complexo do sistema econômico, o intuito principal do presente trabalho foi apontar algumas das possibilidades de avanço da Economia sugeridas por esses elementos teóricos. Buscou-se, nesse sentido, a realização de um enquadramento teórico-metodológico baseado na satisfação de cinco requisitos para uma abordagem que lide adequadamente com as características do sistema econômico que se mostram essenciais à compreensão de sua dinâmica complexa.

Apesar do longo caminho a ser percorrido, tanto do ponto de vista teórico, quanto do ponto de vista estritamente instrumental, uma abordagem micromacrodinâmica, tal como uma mescla de elementos teóricos simonianos, póskeynesianos, kaleckianos, neoschumpeterianos e da abordagem da complexidade parece apontar em uma direção fecunda ao incremento do poder explicativo - e quiçá do preditivo - e da Economia, especialmente porque busca nortear o progresso da teoria pela explicação devida de seu objeto. A contextualização teóricometodológica que envolve a Economia, enquanto ciência, e o consequente progresso 
científico que dela pode decorrer, por sua vez, apresenta consequências práticas e sociais de fundamental importância, principalmente na medida em que baseia a formulação de políticas, com os mais diversos objetivos, dentre eles o que nos parece ser o mais caro: promover bem estar e desenvolvimento socioeconômico.

\section{Referências bibliográficas}

ARTHUR, W. B. Out of equilibrium economics and agent-based modeling. In: JUDD, K.; TESFATSION, L. (Ed.). Handbook of computational economics. V. 2: Agent-based computational economics. North-Holland: Elsevier, 2005. Disponível em: $\underline{\text { www.santafe.edu. }}$

ARTHUR, W. B.; DURLAUF, S.; LANE, D. Introduction. In: ARTHUR, W. Brian; DURLAUF, Steven N.; LANE, David A. (Ed.). The economy as an evolving complex system II. Reading, MA: Addison-Wesley, 1997.

BOLAND, L. Methodology for a new microeconomics. The critical foundations. Boston: Allen \& Unwin, 1986.

CARDOSO, F. G.; LIMA, G. T. A visão de Keynes do sistema econômico como um todo orgânico complexo. Economia e Sociedade, Campinas, v. 17, n. 4, p. 359338, 2008.

CARLIN; SOSKICE. Macroeconomics. Oxford: Oxford University Press, 2006.

COLANDER, D.; HOWITT, P.; KURMAN, A.; LEIJONHUFVUD, A.; MEHRLING, P. Beyond DSGE models: toward an empirically based macroeconomics. American Economic Review: Papers and Proceedings, v. 98, n. 2, p. 236-240, 2008.

DAVIDSON, P. Rational expectations: a fallacious foundation for studying crucial decision-making processes. Journal of Post Keynesian Economics, 1982.

DOSI, G.; EGIDI, M. Substantive and procedural uyncertainty: an exploration of economic behaviours in changing environments. Journal of Evolutionary Economics, Berlin, v. 1, n. 2, p. 145-168, 1991.

DUARTE, P. Recent developments in macroeconomics: the DSGE approach to business cycles in perspective. In: DAVIS, J. B.; HANDS, D. W. (Ed.). The Elgar companion to recent economic methodology. Cheltenham: Edward Elgar Publishing, 2011.

DWECK, E. Uma análise da interação micro-macro com base em um modelo dinâmico multissetorial de simulação. Tese (Doutorado-IE/UFRJ, Rio de Janeiro, 2006. 
ELSTER, J. Ulysses and the sirens: studies in rationality an irrationality. Cambridge: Cambridge University Press. 1979

FOLEY, D. Unholy trinity: labor, capital, and land in the new economy. London: Routledge, 2003.

FOLEY, D. The strange history of the economic agent. Disponível em: http://homepage.newschool.edu/ foleyd/ecagent.pdf.

GALI, J. Monetary policy, inflation, and the business cycle - an introduction to the new Keynesian framework. Princeton: Princeton University Press, 2008.

GLEISER, I. Caos e complexidade - a evolução do pensamento econômico. Rio de Janeiro: Editora Campus, 2002.

HOLLAND, J. H. Hidden order: how adaptation builds complexity. New York: Basic Books, 1995.

KALECKI, M. (1954). Teoria da dinâmica econômica. Rio de Janeiro: Editora Nova Cultural, 1985. (Coleção Os Economistas).

KEYNES, J. M. (1936). A teoria geral do emprego, do juro e da moeda. Rio de Janeiro: Editora Nova Cultural, 1985. (Coleção Os Economistas).

KIRMAN, A. P. The economy as an interactive system: In: ARTHUR, W. Brian; DURLAUF, Steven N.; LANE, David A. (Ed.). The economy as an evolving complex system II. Reading, MA: Addison-Wesley, 1999.

KNUDSEN, C. Economics with Institutions - Agenda for methodological enquiry. In: MAKI, U.; GUSTAFSSON, B.; KNUDSEN, C. (Ed.). Rationality \& Institutions \& Economic Methodology. London: Routledge, 1993.

LAVOIE, M. A post-Keynesian amendment to the new consensus on monetary policy. Metroeconomica, v. 57, n. 2, p. 165-192, 2006.

MINSKY, H. Can "it” happen again? Essays on instability and finance. New York: M. E. Sharpe, 1982.

NELSON, R.; WINTER, S. An evolutionary theory of economic change. Cambridge, Mass.: Harvard University Press, 1982.

PERONA, E. Ciencias de la complejidad: ¿ la economía del siglo 21? Córdoba, Argentina: Universidad Nacional de Córdoba, 2004.

POSSAS, M. L. Dinâmica e ciclo econômico em oligopólio. Tese (Doutorado)Depe/Unicamp, 1983.

POSSAS, M. L. Um modelo dinâmico multissetorial. Pesquisa e Planejamento Econômico, v. 14, n. 2, ago. 1984. 
POSSAS, M. L. A dinâmica da economia capitalista: uma abordagem teórica. São Paulo: Brasiliense, 1987.

PRADO, E. F. Microeconomia reducionista e microeconomia sistémica. Nova Economia, Belo Horizonte, v. 16, n. 2, p. 303-322, maio/ago. 2006.

ROMER, D. Advanced macroeconomics. $3^{\text {rd }}$ ed. New York: Mc Graw-Hill, 2006.

SHACKLE, G. L. S. Uncertainty in economics. Cambridge: Cambridge University Press, 1955.

SCHUMPETER, J. A. (1912). A teoria do desenvolvimento econômico. Rio de Janeiro: Editora Nova Cultural, 1985. (Coleção Os Economistas).

SCHUMPETER, J. A. (1943). Capitalismo, socialismo e democracia. Rio de Janeiro: Editora Fundo de Cultura, 1961.

SIMON, H. A behavioral model of rational choice. The Quarterly Journal of Economics, v. 69, n. 1, p. 99-118, Feb. 1955.

SIMON, H. Rationality as process and as product of thought. The American Economic Association, v. 68, n. 2, p. 1-16, May 1978.

SIMON, H. From substantive to procedural rationality. In: HAHN, F.; HOLLIS, M. (Ed.). Philosophy and economic theory. New York: Oxford University Press, 1979.

TAYLOR, L. Reconstructing macroeconomics. Cambridge: Harvard University Press, 2004.

VEBLEN, T. B. (1898). Why is economics not an evolutionary science? The Quarterly Journal of Economics, v. 12, n. 4, p. 373-397, 2004.

VERCELLI, A. Methodological foundations of macroeconomics: Keynes and Lucas. Cambridge: Cambridge University Press, 1991.

WOODFORD, M. Interest and prices: foundations of a theory of monetary policy. Princeton: Princeton University Press, 2003.

ZAMAGNI, S. Microeconomic theory - an introduction. [s.l.]: Greg Revivals, 1993. 